\title{
Research Article \\ Strong Convergence of a Modified Halpern's Iteration for Nonexpansive Mappings
}

\author{
Liang-Gen Hu \\ Department of Mathematics, Ningbo University, Ningbo 315211, China \\ Correspondence should be addressed to Liang-Gen Hu, hulianggen@yahoo.cn \\ Received 12 September 2008; Accepted 9 December 2008 \\ Recommended by Jerzy Jezierski \\ The purpose of this paper is to consider that a modified Halpern's iterative sequence $\left\{x_{n}\right\}$ \\ converges strongly to a fixed point of nonexpansive mappings in Banach spaces which have a \\ uniformly Gâteaux differentiable norm. Our result is an extension of the corresponding results. \\ Copyright (c) 2008 Liang-Gen Hu. This is an open access article distributed under the Creative \\ Commons Attribution License, which permits unrestricted use, distribution, and reproduction in \\ any medium, provided the original work is properly cited.
}

\section{Introduction}

Let $E$ be a real Banach space and $C$ a nonempty closed convex subset of $E$. We denote by $J$ the normalized duality map from $E$ to $2^{E^{*}}$ ( $E^{*}$ is the dual spaces of $E$ ) defined by

$$
J(x)=\left\{f \in E^{*}:\langle x, f\rangle=\|x\|^{2}=\|f\|^{2}, \forall x \in E\right\} .
$$

A mapping $T: C \rightarrow C$ is said to be nonexpansive if $\|T x-T y\| \leq\|x-y\|$, for all $x, y \in C$. We denote by Fix $(T)=\{x \in C: T x=x\}$ the set of fixed points of $T$. In the last ten years, many papers have been written on the approximation of fixed point for nonlinear mappings by using some iterative processes (see, e.g., [1-18]).

An explicit iterative process was initially introduced, in 1967, by Halpern [3] in the framework of Hilbert spaces, that is, Halpern's iteration. For any $u, x_{0} \in C$, the sequence $\left\{x_{n}\right\}$ is defined by

$$
x_{n+1}=\alpha_{n} u+\left(1-\alpha_{n}\right) T x_{n}, \quad \forall n \geq 0,
$$

where $\left\{\alpha_{n}\right\} \subset[0,1]$. He proved that the sequence $\left\{x_{n}\right\}$ converges weakly to a fixed point of $T$, where $\alpha_{n}=n^{-a}, a \in(0,1)$. In 1977, Lions [8] further proved that the sequence $\left\{x_{n}\right\}$ converges 
strongly to a fixed point of $T$ in a Hilbert space, where $\left\{\alpha_{n}\right\}$ satisfies the following conditions:

$$
\begin{aligned}
& \text { (C1) } \lim _{n \rightarrow \infty} \alpha_{n}=0, \\
& \text { (C2) } \sum_{n=0}^{\infty} \alpha_{n}=+\infty, \\
& \text { (C3) } \lim _{n \rightarrow \infty} \frac{\left|\alpha_{n+1}-\alpha_{n}\right|}{\alpha_{n+1}^{2}}=0 .
\end{aligned}
$$

But, in $[3,8]$, the real sequence $\left\{\alpha_{n}\right\}$ excluded the canonical choice $\alpha_{n}=1 /(n+1)$. In 1992, Wittmann [16] proved, still in Hilbert spaces, the strong convergence of the sequence (1.2) to a fixed point of $T$, where $\left\{\alpha_{n}\right\}$ satisfies the following conditions:

$$
\begin{aligned}
& \text { (C1) } \lim _{n \rightarrow \infty} \alpha_{n}=0 \\
& \text { (C2) } \sum_{n=0}^{\infty} \alpha_{n}=+\infty \\
& \text { (C4) } \sum_{n=1}^{\infty}\left|\alpha_{n+1}-\alpha_{n}\right|<+\infty .
\end{aligned}
$$

The strong convergence of Halpern's iteration to a fixed point of $T$ has also been proved in Banach spaces (see, e.g., $[2,6,10-12,14,15,17,18])$. Reich $[10,11]$ has showed the strong convergence of the sequence (1.2), where $\left\{\alpha_{n}\right\}$ satisfies the conditions (C1), (C2), and (C5). $\left\{\alpha_{n}\right\}$ is decreasing (noting that the condition (C5) is a special case of condition (C4)). In 1997, Shioji and Takahashi [12] extended Wittmann's result to Banach spaces. In 2002, Xu [17] obtained a strong convergence theorem, where $\left\{\alpha_{n}\right\}$ satisfies the following conditions: (C1), (C2), and (C6). $\lim _{n \rightarrow \infty}\left(\left|\alpha_{n+1}-\alpha_{n}\right| / \alpha_{n+1}\right)=0$. In particular, the canonical choice of $\alpha_{n}=1 /(n+1)$ satisfies the conditions (C1), (C2), and (C6).

However, is a real sequence $\left\{\alpha_{n}\right\}$ satisfying the conditions (C1) and (C2) sufficient to guarantee the strong convergence of the Halpern's iteration (1.2) for nonexpansive mappings? It remains an open question.

Some mathematician considered the open question. A partial answer to this question was given independently by C. E. Chidume and C. O. Chidume [2] and Suzuki [14]. They defined the sequence $\left\{x_{n}\right\}$ by

$$
x_{n+1}=\alpha_{n} u+\left(1-\alpha_{n}\right)\left((1-\delta) x_{n}+\delta T x_{n}\right),
$$

where $\delta \in(0,1), I$ is the identity, and obtained the strong convergence of the iteration (1.5), where $\left\{\alpha_{n}\right\}$ satisfies the conditions (C1) and (C2). Recently, $\mathrm{Xu}$ [18] gave another partial answer to this question. He obtained the strong convergence of the iterative sequence

$$
x_{n+1}=\alpha_{n}\left((1-\delta) u+\delta x_{n}\right)+\left(1-\alpha_{n}\right) T x_{n}
$$

where $\delta \in(0,1)$ and $\left\{\alpha_{n}\right\}$ satisfies the conditions (C1) and (C2). 
Inspired and motivated by the above researches, we introduce a modified Halpern's iteration. For any $u, x_{0} \in C$, the sequence $\left\{x_{n}\right\}$ is defined by

$$
x_{n+1}=\alpha_{n} u+\beta_{n} x_{n}+\gamma_{n} T x_{n}, \quad n \geq 0,
$$

where $\left\{\alpha_{n}\right\},\left\{\beta_{n}\right\}$, and $\left\{\gamma_{n}\right\}$ are three real sequences in $(0,1)$, satisfying $\alpha_{n}+\beta_{n}+\gamma_{n}=1$. Clearly, the iterative sequence $(\mathrm{I})$ is a natural generalization of the well-known iterations.

(i) If, for all $n$, we take $\beta_{n} \equiv 0$ in (I), then the sequence (I) reduces to Halpern's iteration (1.2).

(ii) If, for all $n$, we take $\alpha_{n} \equiv 0$ in (I), then the sequence (I) reduces to Mann iteration.

The purpose of this paper is to present a significant answer to the above open question. we will show that the sequence $\left\{\alpha_{n}\right\}$ satisfying the conditions (C1) and (C2) is sufficient to guarantee the strong convergence of the modified Halpern's iterative sequence for nonexpansive mappings. As we will see, our theorem extends the corresponding results in three aspects. (1) The real sequence $\left\{\alpha_{n}\right\}$ satisfies only the conditions (C1) and (C2). (2) In contrast with the results $[2,14]$, we replace the sequence $\left\{\left(1-\alpha_{n}\right)(1-\delta)\right\}$ in $(1.5)$ by an arbitrary sequence $\left\{\beta_{n}\right\}$ in $(0,1)$. (3) In contrast with the result [18], we replace the sequence $\left\{\alpha_{n} \delta\right\}$ in (1.6) by an arbitrary sequence $\left\{\beta_{n}\right\}$ in $(0,1)$.

\section{Preliminaries}

A Banach space $E$ is said to have a Gâteaux differentiable norm if the limit

$$
\lim _{t \rightarrow 0} \frac{\|x+t y\|-\|x\|}{t}
$$

exists for each $x, y \in U$, where $U=\{x \in E:\|x\|=1\}$. E is called a uniformly Gâteaux differentiable norm if for each $y \in U$, the limit is attained uniformly for $x \in U$. It is well known that if the norm of $E$ is uniformly Gâteaux differentiable norm, then the duality mapping is single-valued and norm-to-weak* uniformly continuous on each bounded subset of $E$.

Lemma 2.1 (see $[9,10])$. Let $C$ be a nonempty closed convex subset of a Banach space $E$ which has uniformly Gâteaux differentiable norm and $T: C \rightarrow C$ a nonexpansive mapping with Fix $(T) \neq \varnothing$. Assume that every nonempty closed convex bounded subset of $C$ has the fixed points property for nonexpansive mappings. Then there exists a continuous path: $t \rightarrow z_{t}, t \in(0,1)$ satisfying $z_{t}=$ $t u+(1-t) T z_{t}$, for any $u \in C$, which converges to a fixed point of $T$.

Lemma 2.2 (see [13]). Let $\left\{x_{n}\right\}$ and $\left\{y_{n}\right\}$ be two bounded sequences in a Banach space E such that

$$
x_{n+1}=\beta_{n} x_{n}+\left(1-\beta_{n}\right) y_{n}, \quad n \geq 0,
$$

where $\left\{\beta_{n}\right\}$ is a sequence in $(0,1)$ such that $0<\liminf _{n \rightarrow \infty} \beta_{n} \leq \limsup _{n \rightarrow \infty} \beta_{n}<1$. Assume

$$
\limsup _{n \rightarrow \infty}\left(\left\|y_{n+1}-y_{n}\right\|-\left\|x_{n+1}-x_{n}\right\|\right) \leq 0 \text {. }
$$

Then $\lim _{n \rightarrow \infty}\left\|y_{n}-x_{n}\right\|=0$. 
Lemma 2.3. Let E be a real Banach space. Then the following inequality holds:

$$
\|x+y\|^{2} \leq\|x\|^{2}+2\langle y, j(x+y)\rangle, \quad \forall x, y \in E, \forall j(x+y) \in J(x+y) .
$$

Lemma 2.4 (see [17]). Let $\left\{a_{n}\right\}$ be a sequence of nonnegative real numbers such that $a_{n+1} \leq\left(1-\delta_{n}\right) a_{n}+\delta_{n} \xi_{n}, \forall n \geq 0$, where $\left\{\delta_{n}\right\}$ is a sequence in $[0,1]$ and $\left\{\xi_{n}\right\}$ is a sequence in $\mathbb{R}$ satisfying the following conditions:

(i) $\sum_{n=1}^{\infty} \delta_{n}=+\infty$;

(ii) $\limsup _{n \rightarrow \infty} \xi_{n} \leq 0$ or $\sum_{n=1}^{\infty} \delta_{n}\left|\xi_{n}\right|<+\infty$;

Then $\lim _{n \rightarrow \infty} a_{n}=0$.

\section{Main results}

Theorem 3.1. Let $C$ be a nonempty closed convex subset of a real Banach space $E$ which has a uniformly Gâteaux differentiable norm. Let $T: C \rightarrow C$ be a nonexpansive mapping with Fix $(T) \neq \varnothing$. Assume that $\left\{z_{t}\right\}$ converges strongly to a fixed point $z$ of $T$ as $t \rightarrow 0$, where $z_{t}$ is the unique element of $C$ which satisfies $z_{t}=t u+(1-t) T z_{t}$ for any $u \in C$. Let $\left\{\alpha_{n}\right\},\left\{\beta_{n}\right\}$, and $\left\{\gamma_{n}\right\}$ be three real sequences in $(0,1)$ which satisfy the following conditions: (C1) $\lim _{n \rightarrow \infty} \alpha_{n}=0$ and (C2) $\sum_{n=0}^{\infty} \alpha_{n}=+\infty$. For any $x_{0} \in C$, the sequence $\left\{x_{n}\right\}$ is defined by the iteration in (I). Then the sequence $\left\{x_{n}\right\}$ converges strongly to a fixed point of $T$.

Proof. Take any $p \in$ Fix $(T)$. From (I), it implies that

$$
\begin{aligned}
\left\|x_{n+1}-p\right\| & =\left\|\alpha_{n}(u-p)+\beta_{n}\left(x_{n}-p\right)+\gamma_{n}\left(T x_{n}-p\right)\right\| \\
& \leq \alpha_{n}\|u-p\|+\left(1-\alpha_{n}\right)\left\|x_{n}-p\right\| .
\end{aligned}
$$

Adopting mathematical induction, we obtain, for all $n \geq 0$,

$$
\left\|x_{n}-p\right\| \leq \max \left\{\left\|x_{0}-p\right\|,\|u-p\|\right\} \text {. }
$$

Therefore, we conclude that the sequence $\left\{x_{n}\right\}$ is bounded. Next, we separate the proof into two cases.

Case $1\left(0<\liminf _{n \rightarrow \infty} \beta_{n} \leq \lim \sup _{n \rightarrow \infty} \beta_{n}<1\right)$. Rewrite the iterative process (I) as follows:

$$
\begin{aligned}
x_{n+1} & =\alpha_{n} u+\beta_{n} x_{n}+\gamma_{n} T x_{n} \\
& =\beta_{n} x_{n}+\left(1-\beta_{n}\right) \frac{\alpha_{n} u+\gamma_{n} T x_{n}}{1-\beta_{n}} \\
& =\beta_{n} x_{n}+\left(1-\beta_{n}\right) y_{n}
\end{aligned}
$$

where

$$
y_{n}=\frac{\alpha_{n}}{1-\beta_{n}} u+\frac{\gamma_{n}}{1-\beta_{n}} T x_{n}, \quad \forall n \geq 0
$$


Since $T$ is a nonexpansive mapping and $\left\{x_{n}\right\}$ is bounded, we get that $\left\{y_{n}\right\}$ and $\left\{T x_{n}\right\}$ are bounded. Manipulating (3.4) yields

$$
\begin{aligned}
y_{n+1}-y_{n}= & \left(\frac{\alpha_{n+1}}{1-\beta_{n+1}}-\frac{\alpha_{n}}{1-\beta_{n}}\right) u+\left(1-\frac{\alpha_{n+1}}{1-\beta_{n+1}}\right)\left(T x_{n+1}-T x_{n}\right) \\
& +\left(\frac{\alpha_{n}}{1-\beta_{n}}-\frac{\alpha_{n+1}}{1-\beta_{n+1}}\right) T x_{n} .
\end{aligned}
$$

Consequently, we have

$$
\begin{aligned}
\left\|y_{n+1}-y_{n}\right\|-\left\|x_{n+1}-x_{n}\right\| \leq & \left|\frac{\alpha_{n+1}}{1-\beta_{n+1}}-\frac{\alpha_{n}}{1-\beta_{n}}\right|\|u\|+\left|1-\frac{\alpha_{n+1}}{1-\beta_{n+1}}\right|\left\|x_{n+1}-x_{n}\right\| \\
& +\left|\frac{\alpha_{n}}{1-\beta_{n}}-\frac{\alpha_{n+1}}{1-\beta_{n+1}}\right|\left\|T x_{n}\right\|-\left\|x_{n+1}-x_{n}\right\| .
\end{aligned}
$$

From the fact that $\left\{x_{n}\right\}$ and $\left\{T x_{n}\right\}$ are bounded and $\lim _{n \rightarrow \infty} \alpha_{n}=0$, it follows that

$$
\limsup _{n \rightarrow \infty}\left(\left\|y_{n+1}-y_{n}\right\|-\left\|x_{n+1}-x_{n}\right\|\right) \leq 0
$$

Hence, by Lemma 2.2, we get

$$
\lim _{n \rightarrow \infty}\left\|y_{n}-x_{n}\right\|=0
$$

Using $\lim _{n \rightarrow \infty} \alpha_{n}=0$ and (3.8), we obtain

$$
\begin{aligned}
\left\|x_{n+1}-\frac{\beta_{n} x_{n}+\gamma_{n} T x_{n}}{1-\alpha_{n}}\right\| & \leq \alpha_{n}\left\|u-\frac{\beta_{n} x_{n}+\gamma_{n} T x_{n}}{1-\alpha_{n}}\right\| \longrightarrow 0, \quad n \longrightarrow \infty \\
\left\|x_{n+1}-x_{n}\right\| & \leq\left(1-\beta_{n}\right)\left\|y_{n}-x_{n}\right\| \longrightarrow 0, \quad n \longrightarrow \infty
\end{aligned}
$$

Clearly,

$$
x_{n}-\frac{\beta_{n} x_{n}+\gamma_{n} T x_{n}}{1-\alpha_{n}}=\frac{\gamma_{n}}{1-\alpha_{n}}\left(x_{n}-T x_{n}\right)
$$

Since $\lim _{n \rightarrow \infty} \alpha_{n}=0$ and $\lim \sup _{n \rightarrow \infty} \beta_{n}<1$, we get that $\liminf _{n \rightarrow \infty} \gamma_{n}>0$. Therefore, from (3.9), and (3.10), we find

$$
\left\|x_{n}-T x_{n}\right\|=\frac{1-\alpha_{n}}{\gamma_{n}}\left\|x_{n}-\frac{\beta_{n} x_{n}+\gamma_{n} T x_{n}}{1-\alpha_{n}}\right\| \longrightarrow 0, \quad n \longrightarrow \infty
$$


From $\lim _{n \rightarrow \infty}\left\|x_{n}-T x_{n}\right\|=0$, it follows that there exists a positive number $N$ such that $t_{n}=$ $\max \left\{\sqrt{\left\|x_{n}-T x_{n}\right\|}, 1 / n\right\}, n>N$. Obviously, we find

$$
\lim _{n \rightarrow \infty} \frac{\left\|x_{n}-T x_{n}\right\|}{t_{n}}=0
$$

Since $z_{t}$ is a unique solution of the equation $z_{t}=t u+(1-t) T z_{t}$, we can write

$$
z_{t_{n}}-x_{n}=\left(1-t_{n}\right)\left(T z_{t_{n}}-x_{n}\right)+t_{n}\left(u-x_{n}\right)
$$

Using Lemma 2.3, we get

$$
\begin{aligned}
\left\|z_{t_{n}}-x_{n}\right\|^{2} \leq & \left(1-t_{n}\right)^{2}\left\|T z_{t_{n}}-x_{n}\right\|^{2}+2 t_{n}\left\langle u-x_{n}, j\left(z_{t_{n}}-x_{n}\right)\right\rangle \\
\leq & \left(1-t_{n}\right)^{2}\left(\left\|T z_{t_{n}}-T x_{n}\right\|+\left\|T x_{n}-x_{n}\right\|\right)^{2}+2 t_{n}\left\langle u-x_{n}, j\left(z_{t_{n}}-x_{n}\right)\right\rangle \\
\leq & \left(1+t_{n}^{2}\right)\left\|z_{t_{n}}-x_{n}\right\|^{2}+\left(1-2 t_{n}+t_{n}^{2}\right)\left\|x_{n}-T x_{n}\right\|\left(2\left\|z_{t_{n}}-x_{n}\right\|+\left\|x_{n}-T x_{n}\right\|\right) \\
& +2 t_{n}\left\langle u-z_{t_{n}}, j\left(z_{t_{n}}-x_{n}\right)\right\rangle .
\end{aligned}
$$

Thus,

$$
\left\langle u-z_{t_{n}}, j\left(x_{n}-z_{t_{n}}\right)\right\rangle \leq \frac{t_{n}}{2}\left\|z_{t_{n}}-x_{n}\right\|^{2}+\frac{\left(1+t_{n}^{2}\right)\left\|x_{n}-T x_{n}\right\|}{2 t_{n}}\left(2\left\|z_{t_{n}}-x_{n}\right\|+\left\|x_{n}-T x_{n}\right\|\right) .
$$

From the fact that $\left\{x_{n}\right\},\left\{z_{t_{n}}\right\}$, and $\left\{T x_{n}\right\}$ are bounded and (3.12), it implies that

$$
\limsup _{n \rightarrow \infty}\left\langle u-z_{t_{n}}, j\left(x_{n}-z_{t_{n}}\right)\right\rangle \leq 0
$$

We know that

$$
\begin{aligned}
\left\langle u-z, j\left(x_{n}-z\right)\right\rangle= & \left\langle u-z, j\left(x_{n}-z\right)-j\left(x_{n}-z_{t_{n}}\right)\right\rangle+\left\langle u-z_{t_{n}}, j\left(x_{n}-z_{t_{n}}\right)\right\rangle \\
& +\left\langle z_{t_{n}}-z, j\left(x_{n}-z_{t_{n}}\right)\right\rangle .
\end{aligned}
$$

Noting the hypothesis that $z_{t_{n}} \rightarrow z \in \operatorname{Fix}(T), n \rightarrow \infty$, and the fact that $\left\{x_{n}\right\}$ is bounded and the duality mapping $j$ is norm-to-weak* uniformly continuous on bounded subset of $E$, we have

$$
\begin{gathered}
\left\langle z-z_{t_{n}} j\left(x_{n}-z_{t_{n}}\right)\right\rangle \longrightarrow 0, \quad n \longrightarrow \infty \\
\left\langle u-z, j\left(x_{n}-z_{t_{n}}\right)-j\left(x_{n}-z\right)\right\rangle \longrightarrow 0, \quad n \longrightarrow \infty .
\end{gathered}
$$


Consequently, from (3.16), (3.17), and the two results mentioned above, we obtain

$$
\limsup _{n \rightarrow \infty}\left\langle u-z, j\left(x_{n}-z\right)\right\rangle \leq 0 .
$$

Estimating (I) yields

$$
\begin{aligned}
\left\|x_{n+1}-z\right\|^{2} & \leq\left\|\beta_{n}\left(x_{n}-z\right)+\gamma_{n}\left(T x_{n}-z\right)\right\|^{2}+2 \alpha_{n}\left\langle u-z, j\left(x_{n+1}-z\right)\right\rangle \\
& \leq\left(1-\alpha_{n}\right)\left\|x_{n}-z\right\|^{2}+2 \alpha_{n}\left\langle u-z, j\left(x_{n+1}-z\right)\right\rangle .
\end{aligned}
$$

Therefore, combining Lemma 2.4 with (3.19) and (3.20), we get that $\lim _{n \rightarrow \infty}\left\|x_{n}-z\right\|=0$.

Case $2\left(\lim _{n \rightarrow \infty} \beta_{n}=1\right)$. Assume that $T_{n} x=\beta_{n} /\left(1-\alpha_{n}\right) x+\gamma_{n} /\left(1-\alpha_{n}\right) T x$, for all $n \geq 0$, then it is easy to see that for each $n \in N, T_{n} x=x$ if and only if $T x=x$, that is, $T_{n}$ has the same set of fixed points of $T$. Rewrite the iterative process (I) as follows:

$$
x_{n+1}=\alpha_{n} u+\left(1-\alpha_{n}\right) T_{n} x_{n} .
$$

Since $\lim _{n \rightarrow \infty} \alpha_{n}=0$ and $\lim _{n \rightarrow \infty} \beta_{n}=1$, and $\left\{T_{n} x_{n}\right\}$ is bounded, we have

$$
\left\|x_{n+1}-x_{n}\right\| \leq \alpha_{n}\|u\|+\gamma_{n}\left\|T_{n} x_{n}\right\| \longrightarrow 0, \quad n \longrightarrow \infty
$$

Consequently, we get that

$$
\left\|x_{n+1}-\frac{\beta_{n} x_{n}+\gamma_{n} T x_{n}}{1-\alpha_{n}}\right\| \leq \alpha_{n}\left\|u-\frac{\beta_{n} x_{n}+\gamma_{n} T x_{n}}{1-\alpha_{n}}\right\| \longrightarrow 0, \quad n \longrightarrow \infty
$$

Combining (3.22) and (3.23) yields

$$
\left\|x_{n}-T_{n} x_{n}\right\| \leq\left\|x_{n}-x_{n+1}\right\|+\left\|x_{n+1}-T_{n} x_{n}\right\| \longrightarrow 0, \quad n \longrightarrow \infty
$$

Adopting the same proof as Case 1 , we can easily conclude that $\lim _{n \rightarrow \infty}\left\|x_{n}-z\right\|=0$.

If $\limsup _{n \rightarrow \infty} \beta_{n}=1$, then we take arbitrarily the two subsequences $\left\{\beta_{n_{i}}\right\}$ and $\left\{\beta_{n_{j}}\right\}$ in $\left\{\beta_{n}\right\}$ such that $\lim _{i \rightarrow \infty} \beta_{n_{i}}=1$ and $\limsup _{j \rightarrow \infty} \beta_{n_{j}}<1$, and we obtain the strong convergence of the sequence $\left\{x_{n}\right\}$ by employing the above-mentioned proof method.

Remark 3.2. If $\lim _{n \rightarrow \infty} \beta_{n}=0$ and $\liminf _{n \rightarrow \infty} \beta_{n}=0$, then, from Xu's results [18] and proof of Theorem 3.1, we obtain the strong convergence theorem.

As direct consequences of Theorem 3.1, we obtain the two following corollaries.

Corollary 3.3 (see [2, Theorem 3.1]). Let $E, C$, and $T$ be as Theorem 3.1. For a fixed $\delta \in(0,1)$, define $S: C \rightarrow C$ by $S x:=(1-\delta) x+\delta T x, \forall x \in C$. Assume that $\left\{z_{t}\right\}$ converges strongly to a fixed point $z$ of $T$ as $t \rightarrow 0$, where $z_{t}$ is the unique element of $C$ which satisfies $z_{t}=t u+(1-t) T z_{t}$, for any 
$u \in C$. Let $\left\{\alpha_{n}\right\}$ be a real sequence in $(0,1)$ satisfying the conditions (C1) and (C2). For any $x_{0} \in C$, the sequence $\left\{x_{n}\right\}$ is defined by

$$
x_{n+1}=\alpha_{n} u+\left(1-\alpha_{n}\right) S x_{n}
$$

Then the sequence $\left\{x_{n}\right\}$ converges strongly to a fixed point of $T$.

Proof. If, in proof of Theorem 3.1, we take $\beta_{n}=\left(1-\alpha_{n}\right)(1-\delta), \lim _{n \rightarrow \infty} \beta_{n}=1-\delta$, then we get the desired conclusion.

Corollary 3.4 (see [18, Theorem 3.1]). Let E be a uniformly smooth Banach space, C a closed convex subset of $E$, and $T: C \rightarrow C$ a nonexpansive mapping such that Fix $(T) \neq \varnothing$. For any sequence $\left\{\alpha_{n}\right\}$ in $(0,1)$ satisfying the conditions $(\mathrm{C} 1)$ and $(\mathrm{C} 2)$, number $\delta \in(0,1)$, and vectors $u, x_{0} \in C$, define a sequence $\left\{x_{n}\right\}$ by the iterative algorithm

$$
x_{n+1}=\alpha_{n}\left(\delta u+(1-\delta) x_{n}\right)+\left(1-\alpha_{n}\right) T x_{n}, \quad n \geq 0 .
$$

Then the sequence $\left\{x_{n}\right\}$ converges strongly to a fixed point of $T$.

Remark 3.5. For any real sequence $\left\{\beta_{n}\right\} \subset(0,1)$, the real sequence $\left\{\alpha_{n}\right\}$ satisfying the two conditions (C1) and (C2) is sufficient for the strong convergence of the iterative sequence (II) for nonexpansive mappings. Therefore, our results give a significant partial answer to the open question.

\section{Acknowledgments}

The authors are grateful to anonymous referees for careful reading of the manuscript and helpful suggestions. (This work was supported partly by National Science Foundation of China (60872095), the Natural Science Foundation of Zhejiang Province (Y606093), K. C. Wong Magna Fund in Ningbo University, and Ningbo Natural Science Foundation (2008A610018)).

\section{References}

[1] F. E. Browder, "Convergence of approximants to fixed points of nonexpansive nonlinear mappings in Banach spaces," Archive for Rational Mechanics and Analysis, vol. 24, no. 1, pp. 82-90, 1967.

[2] C. E. Chidume and C. O. Chidume, "Iterative approximation of fixed points of nonexpansive mappings," Journal of Mathematical Analysis and Applications, vol. 318, no. 1, pp. 288-295, 2006.

[3] B. Halpern, "Fixed points of nonexpanding maps," Bulletin of the American Mathematical Society, vol. 73, no. 6, pp. 957-961, 1967.

[4] L.-G. Hu, T.-J. Xiao, and J. Liang, "Generalized Mann iterations for approximating fixed points of a family of hemicontractions," Fixed Point Theory and Applications, vol. 2008, Article ID 824607, 9 pages, 2008.

[5] J. S. Jung, "Convergence on composite iterative schemes for nonexpansive mappings in Banach spaces," Fixed Point Theory and Applications, vol. 2008, Article ID 167535, 14 pages, 2008.

[6] T.-H. Kim and H.-K. Xu, "Strong convergence of modified Mann iterations," Nonlinear Analysis: Theory, Methods \& Applications, vol. 61, no. 1-2, pp. 51-60, 2005.

[7] W. A. Kirk, "Locally nonexpansive mappings in Banach spaces," in Fixed Point Theory, vol. 886 of Lecture Notes in Math., pp. 178-198, Springer, Berlin, Germany, 1981.

[8] P.-L. Lions, "Approximation de points fixes de contractions," Comptes Rendus de l'Académie des Sciences. Série A-B, vol. 284, no. 21, pp. A1357-A1359, 1977. 
[9] C. H. Morales and J. S. Jung, "Convergence of paths for pseudocontractive mappings in Banach spaces," Proceedings of the American Mathematical Society, vol. 128, no. 11, pp. 3411-3419, 2000.

[10] S. Reich, "Strong convergence theorems for resolvents of accretive operators in Banach spaces," Journal of Mathematical Analysis and Applications, vol. 75, no. 1, pp. 287-292, 1980.

[11] S. Reich, "Approximating fixed points of nonexpansive mappings," PanAmerican Mathematical Journal, vol. 4, no. 2, pp. 23-28, 1994.

[12] N. Shioji and W. Takahashi, "Strong convergence of approximated sequences for nonexpansive mappings in Banach spaces," Proceedings of The American Mathematical Society, vol. 125, no. 12, pp. 3641-3645, 1997.

[13] T. Suzuki, "Strong convergence theorems for infinite families of nonexpansive mappings in general Banach spaces," Fixed Point Theory and Applications, vol. 2005, no. 1, pp. 103-123, 2005.

[14] T. Suzuki, "A sufficient and necessary condition for Halpern-type strong convergence to fixed points of nonexpansive mappings," Proceedings of the American Mathematical Society, vol. 135, no. 1, pp. 99$106,2007$.

[15] W. Takahashi and Y. Ueda, "On Reich's strong convergence theorems for resolvents of accretive operators," Journal of Mathematical Analysis and Applications, vol. 104, no. 2, pp. 546-553, 1984.

[16] R. Wittmann, "Approximation of fixed points of nonexpansive mappings," Archiv der Mathematik, vol. 58, no. 5, pp. 486-491, 1992.

[17] H.-K. Xu, "Iterative algorithms for nonlinear operators," Journal of the London Mathematical Society, vol. 66, no. 1, pp. 240-256, 2002.

[18] H.-K. Xu, "WITHDRAWN: a strong convergence theorem for nonexpansive mappings," Journal of Mathematical Analysis and Applications. In press. 